\title{
Clinical effectiveness of anterior cervical discectomy and fusion to treat cervical spondylosis using anterior cervical system
}

\author{
Prashant Kumar $^{1 *}$, Mohit Kumar ${ }^{2}$, Pooja Rawat $^{2}$, Gaurav Luthra ${ }^{2}$
}

${ }^{1}$ Centre of Excellence in Industrial and Product Design, Punjab Engineering College, Chandigarh, India

${ }^{2}$ Regulatory Department, Auxein Medical Pvt. Ltd. Sonipat, Haryana, India

Received: 09 September 2019

Revised: 04 October 2019

Accepted: 05 October 2019

\author{
*Correspondence: \\ Dr. Prashant Kumar, \\ E-mail: rajput.prashant2013@gmail.com
}

Copyright: (C) the author(s), publisher and licensee Medip Academy. This is an open-access article distributed under the terms of the Creative Commons Attribution Non-Commercial License, which permits unrestricted non-commercial use, distribution, and reproduction in any medium, provided the original work is properly cited.

\begin{abstract}
Background: Age related problems in the spinal segment bring about a degenerative course known as spondylosis. Hereditary, condition, and word related impacts may play a role. These spondylosis changes may bring about direct compressive and ischemic dysfunction of the spinal cord known as cervical spondylosis.

Methods: In this examination 30 patients were selected with cervical spondylosis with, in the fundamental, myelography includes, and treated by anterior cervical discectomy and fusion using anterior cervical system (Apex plate) provided by Auxein Medical Pvt. Ltd. These patients are separated in two gatherings, one is male (12) and another female (18). Functional outcome of the patients was assessed by the visual analogue scale score at postoperative follow up at 1months, 3 months, 6 months, 9 months and 1 year.

Results: The after effects of this clinically treatment have by and large been great and this is especially so in old patients with an alternate injury, for example, C1-C2, C2-C3, C3-C4, C4-C5, C5-C6 and C6-C7.

Conclusions: The finish of this examination is that the cervical spondylosis patients might be oversees effectively with anterior cervical discectomy and fusion utilizing anterior cervical system. Effectively clinical outcomes in regards to indications improvement and general fulfillment with the surgery were excellent with low rate of complications.
\end{abstract}

Keywords: Anterior cervical, Spondylosis, Discectomy and fusion, Cervical fracture

\section{INTRODUCTION}

The neck, additionally called the cervical spine, is a welldesigned structure of bones, nerves, muscles, tendons, and ligaments. The cervical spine is sensitive- lodging the spinal line that sends messages from the mind to control all parts of the body; while additionally amazingly solid and adaptable, enabling the neck to move in all direction. The cervical spine is comprised of 7 vertebrae as shown in. The initial two, $\mathrm{C} 1$ and $\mathrm{C} 2$, are exceptionally specific and are given remarkable names: atlas and axis, respectively. C3-C7 is increasingly great vertebrae, having a body, pedicles, laminae, spinous procedures, and facet joints.
Spondylotic (age-related degenerative changes of the spine) or non-spondylotic injuries that influence the cervical vertebrae can prompt compression of adjoining nervous structures coming about in myelopathic (spinal line root) or radiculopathy (spinal nerve origin) side effects including torment and loss of function. ${ }^{1-4}$ Nonspondylotic lesions (injury, tumors, disease and other rarer causes) take up a smaller proportion of myelopathic or radiculopathy causes, however can bring about significant adjustment of the structural anatomy. ${ }^{1,2,5-7}$

The pathogenesis and no less the administration of cervical spondylotic myelopathy stays somewhat open to discuss. There have been several of careful examinations 
on the management, which has generally fallen into the preservationist and the surgical. Preservationist the executives comprise generally of immobilization by cervical collar and surgical administration is isolated into anterior and posterior approach. Our own criteria for the utilization of a surgical methodology have changed throughout the years however have all in all been partitioned into a decompressive approach for the old with generally stable spines and different degrees of plate impression impinging on the cord, and one sor conceivably two level anterior cervical approaches where one or at most two discs seem, by all accounts, to be embroiled in the spondylosis, more often than not in fairly more youthful patients. ${ }^{8}$ A gathering of cases exists, in any case, especially in the very elderly, where C $3 / 4$ degeneration regularly with subluxation at this level, goes to the improvement of an extremely stationary cervical spine with advance spondylosis at different levels. This examination records the aftereffects of a significantly single level foremost cervical fusion, utilizing the Cloward strategy, in a continuous arrangement of 30 patients (12 males and 18 females), who had either given cervical spondylotic myelopathy.

The aim of this research was to examine the clinical effectiveness of anterior cervical discectomy and fusion to treat cervical spondylosis using anterior cervical system (Apex plate).

\section{METHODS}

This study was a prospective and pilot study conducted at Sant Parmanand Hospital, New Delhi, India with a one year between January 2018 to March 2019. The patients were selected for surgery on the basis of the clinical findings of cervical myelopathy with evidence that this was due to cervical spondylosis. There were 12 males and 18 females. $14(46.7 \%)$ less than 50 years old and 16 $(53.3 \%)$ greater than 50 years old. Routine clinical methods of neurological assessment were employed and, in the main, the symptoms were those of a cervical myelopathy associated with nerve root involvement in the upper limbs.

The classification of inability is that proposed by Symon and Lavender which is adjusted from the Less and Aldren-Turner. It is:

- Mild inability in which the patient however mindful of variation from the norm isn't impeded in his regular day to day existence and except if different components are available is at all day work.

- Moderate incapacity, a patient who is obviously disabled in his ordinary task however is in part at work.

- Severe non-bedbound, the patient can't work yet is as yet ready to get about inside.

- Severe laid up the patient is restricted to bed with generous limb weakness or ataxia, unfit to stand or walk unsupported.
As indicated by American Society of Anesthesiologists physical status classification system, out of 30 patients, 6 patients were having grade I (healthy patients), 15 patients felt under grade II (patients with mild methodical disease) and 9 patients were under grade III (sever systematic disease) with no report of past medical procedure on the influenced break.

Indigenously manufactured implants were utilized according to treatment plan. The anterior cervical discectomy and fusion was performed by utilizing the anterior cervical system (Apex plate) to all patients as shown in Figure 1. Implants utilized in the surgery process were arranged from titanium alloy (Ti-6AL-4V) according to ISO 5832-3 (Auxein Medical Pvt. Ltd, Sonipat). All patients were treated with titanium alloy implants.

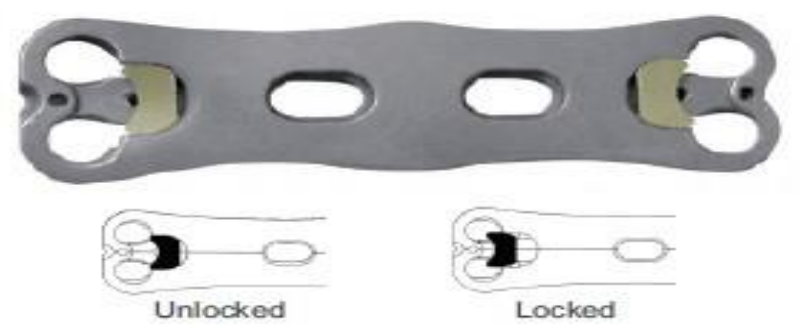

Figure 1: Anterior cervical system (Apex plate).

The surgery was performed with the patient under general anesthesia. One-month post-medical procedure X-ray was utilized to assess the outcomes. With guidance of general physical activities, the imaging information indicated great position of implants. Utilizing the 10-point score information framework, visual analogue scale was utilized to survey the outcome.

Postoperative conditions were evaluated regarding pain. After osteosynthesis, X-ray beam was taken once every 3 months for all patients. These radiographs were inspected for hard association, implants disappointment, plate movement, and broadening of the hook hole. All radiographic estimations were performed by a similar specialist.

\section{Inclusion criteria}

Male or female, skeletally mature patient and who is willing and able to complete required study visits or assessments.

\section{Exclusion criteria}

The participant may not enter the study if any of the following such as: subjects with a disease entity or condition that totally precludes the possibility of bony fusion such as known active cancer, etc., subject having any neuromuscular disorder which would create an unacceptable risk of fixation failure or complications in 
postoperative care, subjects with substance abuse/alcohol issues, subjects who are incarcerated or have pending incarceration, subject having infection local to the operative site, any uncontrolled systemic disease that, in the opinion of the investigator, would preclude participation in the study (e.g., unstable medical status including uncontrolled elevated blood pressure, cardiovascular disease, and glycemic control) or put the subject at risk due to study treatment or procedures, subject with rapid joint disease, bone absorption, osteopenia, and/or osteoporosis and subject having suspected or documented metal allergy or intolerance.

\section{RESULTS}

Out of 30 patients, 18 women $(60 \%)$ and $12(40 \%)$ were involved in the study. The average mean age of patients was 50 years shown in Table 1. Myelography was invariably was used, and anteroposterior and lateral views were taken of the head in full extension and flexion while the patient was in the prone position. Anterior cervical fusion at various levels in the cervical spine of patients as shown in Table 2.

Table 1: Demographic data.

\begin{tabular}{|ll|}
\hline Demography & \\
\hline Average age in years (range) & $35-60(32.5)$ \\
\hline Gender, N (\%) & \\
\hline Male & $12(40)$ \\
\hline Female & $18(60)$ \\
\hline
\end{tabular}

Table 2: Anterior cervical fusion at various levels in the cervical spine and patients.

\begin{tabular}{|ll|}
\hline Levels & Total patients (\%) \\
\hline C1-C2 & $3(10)$ \\
\hline C2-C3 & $9(30)$ \\
\hline C3-C4 & $3(10)$ \\
\hline C4-C5 & $4(13.32)$ \\
\hline C5-C6 & $3(10)$ \\
\hline C6-C7 & $3(10)$ \\
\hline C1/2-C2/3 & $1(3.33)$ \\
\hline C2/3-C3/4 & $1(3.33)$ \\
\hline C3/4-C4/5 & $3(10)$ \\
\hline
\end{tabular}

In our study, cervical level C2-C3 was involved in nine patients, $\mathrm{C} 1-\mathrm{C} 2$ involved in 3 patients, $\mathrm{C} 3-\mathrm{C} 4$ in 3 patients, $\mathrm{C} 4-\mathrm{C} 5$ in 4 patients, $\mathrm{C} 5-\mathrm{C} 6$ in 3 patients and C6$\mathrm{C} 7$ in 3 patients. $\mathrm{C} 2-\mathrm{C} 3$ and $\mathrm{C} 3-\mathrm{C} 4$ involved in 1 patient, $\mathrm{C} 1-\mathrm{C} 2$ and $\mathrm{C} 2-\mathrm{C} 3$ in 1 patient and $\mathrm{C} 3-\mathrm{C} 4$ and $\mathrm{C} 4-\mathrm{C} 5$ in 3 patients. From this it develops that the $\mathrm{C} 2-\mathrm{C} 3$ disc was all the more ordinarily engaged with the age gathering, reliable with our perception that degeneration of this disc, for the most part connected with some subluxation, happens in the old after a spondylotic fragment including C4-C5, C5-C6 and sometimes C6-C7 has virtually fused. The excessive mobility forced upon $\mathrm{C} 3-\mathrm{C} 4$ under these circumstances produces its degeneration last in the course of the diseases.

Clinical assessment for pain, aesthetic appearance and fulfillment with treatment was appraised by patients on a visual analog scale (VAS) score (most extreme score, 10 focuses) at the final development in Table 3. The mean VAS score (greatest score, 10 points) at the last development is appeared in Table 4. The follow-up of patients was taken at 1, 3, 6, 9 and 12th months in a year demonstrated great clinical outcomes.

Table 3: Patient satisfaction data $(n=30)$.

\begin{tabular}{|lll|}
\hline Evaluation parameter & $\begin{array}{l}\text { Satisfied } \\
\text { N }(\%)\end{array}$ & $\begin{array}{l}\text { Not satisfied } \\
\text { N }(\%)\end{array}$ \\
\hline Pain & $25(83.33)$ & $5(16.67)$ \\
\hline Aesthetic appearance & $27(90)$ & $3(10)$ \\
\hline
\end{tabular}

Table 4: VAS score (1 year clinical follow up).

\begin{tabular}{|ll|}
\hline VAS score (in months) & $\mathbf{N}(\%)$ \\
\hline $\mathbf{1}$ & $6.30(63)$ \\
\hline $\mathbf{3}$ & $5.03(50.3)$ \\
\hline $\mathbf{6}$ & $2.67(26.7)$ \\
\hline $\mathbf{9}$ & $1.67(16.7)$ \\
\hline $\mathbf{1 2}$ & $0.6(6)$ \\
\hline
\end{tabular}

The mean VAS score for pain $[0=$ no pain, $10=$ extreme pain] was 8.267. The mean VAS score after 12th month is 0.6 , means that the patients have no pain and good feeling.

\section{DISCUSSION}

The surgical treatment of cervical disorders and disc resulting in neurological symptoms have been well described. $^{9-10}$ Results is carried out on the basis of patients review. The treatment of spondylosis by anterior cervical discectomy and fusion was very well. The result was taken after every 3 months. Female patients were more susceptible in study. Physical therapy post-surgery for cervical spondylosis starts immediately. Under the supervision of a physical therapist sit on the edge of the bed and stand with support. Wearing cervical brace recommended. While patients are frequently urged to stand and sit (with help if necessary) within twenty- four hours after medical procedure, movement is drawn closer steadily and in a guided way to stay away from damage and difficulties. Patient need to keep neck set up except if explicitly taught to evacuate. Antibiotics given intravenously for 24 hours to help prevent infection. Pain medication is available to ensure comfort. Brace is to be continued for 3 months postoperatively and patient removed it in average 3 months. Cervical radiographs with anteroposterior, lateral view were obtained beginning with the 1 st month, 3rd month, 6th month, 9th month and 12th month (on 1 year) calculated from the day of surgery to check the stability. With 125 patients 
Moussa et al have treated cervical spondylosis by anterior cervical fusion. ${ }^{11}$

A study conducted by Mandal et al recruited 15 of the 17 patients, performed Hirabayashi technique (canal expensive single door laminoplasty) and $87 \%$ experienced relief of their symptoms. ${ }^{12}$ Wang et al reported that patients receiving miniplates experienced significantly less pain at 21.2 months as measured by a VAS scale (27.2 mm 30.4) compared with patients receiving no plates $(38.8 \mathrm{~mm} \mathrm{30.2,} \mathrm{p}=0.046) .{ }^{13}$ Moreover, reoperation in our study was $0 \%$, total, complication was only $4 \%$ and non-consolidation was similar to other series.

The anterior cervical discectomy and fusion technique applied in the fixation procedure which has good achieving fusion and stability. The fusion status was judged, an evaluation done by an independent observer. All the patients included in the study showed satisfactory bony fusion as judged by solid fusion at both facets joint. Radiological fusion started was seen earliest on 3rd month check X-ray. There were no complications noticed related to spinal biomechanics in study and hardware related complications were not encountered in this. Four case of dysphasia was reported which was not related to implant, according to the independent investigator it is medical condition, patient were suggested and recommended for the physical therapy and physiotherapy, on regular follow up visits patient was found to have resolved dysphasia complication. Patient started normal routine activist from six month without any complication.

\section{CONCLUSION}

Our experience with the Apex plate used for the treatment of cervical spondylosis showed excellent results with low rates of complications at different cervical sites. The preoperative conditions have been nil with no non-union reported. It is concluded that the anterior cervical approach in the treatment of cervical spondylosis has much to offer if the patients are carefully selected. Continued and marked improvement is common.

Funding: No funding sources Conflict of interest: None declared

Ethical approval: The study was approved by the institutional ethics committee

\section{REFERENCES}

1. Shelerud RA, Paynter KS. Rarer causes of radiculopathy: spinal tumors, infections, and other unusual causes. Phys Med Rehabil Clin N Am. 2002;13:645-96.

2. Tetreault L, Goldstein CL, Arnold P. Degenerative Cervical Myelopathy: A Spectrum of Related Disorders Affecting the Aging Spine. Neurosurgery. 2015;77(4):51-67.

3. Carette S, Fehlings MG. Cervical Radiculopathy. N Engl J Med. 2005;353:392-9.

4. Baptiste DC, Fehlings MG. Pathophysiology of cervical myelopathy. Spine J. 2006;6:190-7.

5. Mobbs RJ, Coughlan M, Thompson R. The utility of $3 \mathrm{D}$ printing for surgical planning and patientspecific implant design for complex spinal pathologies: case report. J Neurosurg Spine. 2017;26:513-8.

6. Xu N, Wei F, Liu X. Reconstruction of the Upper Cervical Spine Using a Personalized 3D-Printed Vertebral Body in an Adolescent with Ewing Sarcoma. Spine. 2016;41:50-4.

7. Li X, Wang Y, Zhao Y. Multilevel 3D Printing Implant for Reconstructing Cervical Spine with Metastatic Papillary Thyroid Carcinoma. Spine 2017;42:1326-30.

8. Adams CBT, Logue V. Studies in cervical spondylotic myelopathy III. Some functional effects of operations for cervical spondylotlc myelopathy. Brain. 1971;94:587-94.

9. ClowardR. B., The anterior approach of removal of ruptured cervical discs. J. Neurosurg. 1958;15:602-17.

10. Cloward RB, Vertebral body fusion for ruptured cervical disc. Description of instruments and operative technic. Amer J Surg.1959;98:722-7.

11. Moussa AH, Nitta M, Symon L. The Results of Anterior Cervical Fusion in Cervical Spondylosis, Acta Neurochinargica. 1983;68:277-88.

12. Mandal S, Banerjee U. Analysis of the outcome in patients with cervical spondylotic myelopathy, undergone canal expansive laminoplasty supported with instrumentation in a group of Indian population: a prospective study. Int J Spine Surg. 2016;10:17.

13. Wang L, Song Y, Liu L. Clinical outcomes oftwo different types of open-door laminoplasties for cervical compressive myelopathy: a prospective study. Neurol India. 2012;60(2):210-6.

Cite this article as: Kumar P, Kumar M, Rawat P, Luthra G. Clinical effectiveness of anterior cervical discectomy and fusion to treat cervical spondylosis using anterior cervical system. Int J Res Orthop 2019;5:1074-7. 